\title{
The distribution and prognosis of anomalous coronary arteries identified by cardiovascular magnetic resonance: 15 year experience from two tertiary centres
}

David P Ripley ${ }^{1,2}$, Ansuman Saha ${ }^{2}$, Albert Teis ${ }^{3}$, Akhlaque Uddin $^{1,2}$, Petra Bijsterveld ${ }^{1}$, Ananth Kidambi ${ }^{1,2}$, Adam K McDiarmid ${ }^{1,2}$, Mohan Sivananthan ${ }^{2}$, Sven Plein ${ }^{1,2}$, Dudley J Pennell ${ }^{3}$ and John P Greenwood ${ }^{1,2^{*}}$

\begin{abstract}
Background: Aberrant coronary arteries represent a diverse group of congenital disorders. Post-mortem studies reveal a high risk of exercise-related sudden cardiac death in those with an anomalous coronary artery originating from the opposite sinus of Valsalva (ACAOS) with an inter-arterial course. There is little documentation of lifetime history and long-term follow-up of patients with coronary artery anomalies.

Methods: Patients with anomalous coronary arteries undergoing cardiovascular magnetic resonance over a 15-year period were identified and classified by anatomy and course. Medical records were reviewed for major adverse cardiovascular events (MACE). Revascularisation or myocardial infarction counted only if occurring in the distribution of the anomalous artery.

Results: Consecutive patients with coronary artery anomalies were retrospectively identified ( $n=172)$. Median follow-up time was 4.3 years (IQR 2.5-7.8, maximum 15.6). 116 patients had ACAOS of which 64 (55\%) had an inter-arterial course (IAC) and 52 (45\%) did not. During follow up 110 ACAOS patients were alive, 5 died and 1 lost to follow-up.

ACAOS patients experienced 58 MACE events (5 cardiovascular deaths, 5 PCI, 24 CABG and 24 had myocardial infarction). 47 MACE events occurred in ACAOS with IAC and 11 in those without $(p<0.0001)$, the statistical difference driven by surgical revascularisation and myocardial infarction.
\end{abstract}

Conclusions: In life, patients with an anomalous coronary artery originating from the opposite sinus of Valsalva taking an IAC have higher rates of both myocardial infarction and surgical revascularisation during long-term follow up, compared to those without IAC.

Keywords: Coronary vessel anomalies, Cardiovascular magnetic resonance, Prognosis

\section{Background}

Aberrant coronary arteries represent a diverse group of congenital disorders which affect between 0.3 to $1.3 \%$ of the unselected general population undergoing cardiac catheterisation $[1,2]$. They are increasingly recognised due to the expansion of advanced non-invasive cardiovascular

\footnotetext{
* Correspondence: j.greenwood@leeds.ac.uk

'Multidisciplinary Cardiovascular Research Centre (MCRC) \& Leeds Institute of Genetics, Health and Therapeutics, University of Leeds, Leeds, UK

2Leeds Teaching Hospitals NHS Trust, Leeds General Infirmary, Leeds, UK
}

Full list of author information is available at the end of the article imaging techniques including computed tomography (CT) imaging and cardiovascular magnetic resonance (CMR).

The majority of coronary anomalies go unrecognised and have no clinical significance, although a minority have been documented to have increased risk of myocardial infarction and ischaemia, congestive heart failure and sudden cardiac death (SCD). Congenital coronary abnormalities are the second leading cause of SCD in the young exceeded only by hypertrophic cardiomyopathy (HCM) [3]. Those with the highest risk include individuals with an anomalous coronary artery originating from the opposite sinus of Valsalva (ACAOS) with this

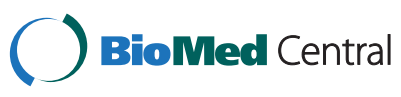

(c) 2014 Ripley et al.; licensee BioMed Central Ltd. This is an Open Access article distributed under the terms of the Creative Commons Attribution License (http://creativecommons.org/licenses/by/2.0), which permits unrestricted use, distribution, and reproduction in any medium, provided the original work is properly credited. The Creative Commons Public Domain Dedication waiver (http://creativecommons.org/publicdomain/zero/1.0/) applies to the data made available in this article, unless otherwise stated. 
risk higher in athletes than non-athletic persons [4]. Furthermore post mortem studies suggest this risk is limited to those ACAOS which take an inter-arterial course (IAC) between the aorta and pulmonary artery (PA), and this has been documented in both anomalous origins of the right coronary artery from the left coronary sinus (right-ACAOS) and in anomalous origins of the left coronary artery from the right coronary sinus (left-ACAOS); the latter appears to carry a higher risk of SCD [5-7]. Other anatomical features which are associated with high risk include intra-mural course, slit-like orifice and angulated take-off which are all thought to contribute to myocardial ischaemia [8].

Surgical intervention in patients with ACAOS, such as re-implantation of the anomalous vessel into the correct coronary sinus, unroofing of the intra-mural course or coronary artery bypass grafting may be performed which in theory prevents ischaemia and/or SCD. There are favourable early outcome data from surgical intervention $[9,10]$ although little data regarding long term follow-up for late complications and outcomes. Although Krasuski et al. demonstrated contrasting results showing similar mortality rates between medically and surgically treated groups with ACAOS [10].

There is little published evidence describing the long term history and long-term follow-up of anomalous coronary arteries in life. The aim of this study was to demonstrate the distribution of anomalous coronary arteries referred for CMR and to document their long-term clinical outcome with respect to major adverse cardiovascular event (MACE) rates. A secondary aim was to confirm whether or not the anatomical course of anomalous coronary arteries conferred differential risk.

\section{Methods}

This study was approved by a regional research ethics committee and the National Information Governance Board for Health and Social Care (NIGB, section 251). Databases from two large UK cardiovascular MR centres were reviewed (Leeds General Infirmary and the Royal Brompton Hospital, London). All patients who were referred for clinically indicated CMR over a 15 year period (1995 to 2010) with anomalous coronary arteries identified on those scans were recorded. All CMR scans were performed with a 1.5 Tesla Philips Intera $\mathrm{CV}$ scanner (Philips Healthcare, Best, The Netherlands) or a 1.5 Tesla Siemens Sonata or Avanto scanner (Siemens Healthcare, Erlangen, Germany).

All CMR images were recalled and independently retrospectively reviewed. The anomalous coronary arteries were classified according to their anatomy and course, following strict criteria (Table 1).

Both the electronic and paper records of all patients were reviewed for MACE. Confirmation of events was

\section{Table 1 Classification of anomalous coronary arteries*}

1. Origin of both RCA and LMS (separate origins) from the right aortic sinus

1a. Course of anomalous LMS between aorta and pulmonary artery (PA)

1b. Course of anomalous LMS not between aorta and PA

2. Origin of both coronary arteries (separate origins) from the left aortic sinus

2a. Course of anomalous RCA between aorta and PA

2b. Course of anomalous RCA not between aorta and PA

3. Anomalous origin of the circumflex coronary artery from the right aortic sinus

3a. Course of anomalous LCX between aorta and PA

3b. Course of anomalous LCX not between aorta and PA

4. Anomalous origin of the left anterior descending artery from the right aortic sinus

4a. Course of anomalous LAD between aorta and PA

4b. Course of anomalous LAD not between aorta and PA

5. Single coronary artery (common origin)

5a. Course of anomalous coronary artery between aorta and PA

5b. Course of anomalous coronary artery not between aorta and PA

6. Anomalous origin or communication of a coronary artery with a cardiac chamber or major thoracic vessel

6a. Abnormal origin from the pulmonary artery or one of its major arterial branches

6b. Abnormal origin from the aorta or one of its major arterial branches

6c. Abnormal communication of a coronary artery with a cardiac chamber or major thoracic vessel (fistula).

7. Miscellaneous/unclassified

*Adapted from Angelini Circulation 2002 [11] and Wilkins Texas Heart Institute Journal 1988 [12].

further clarified from the general practitioner records. Their vital status (dead or alive) was ascertained from National Health Service Spine electronic record and if the patient was dead, the cause of death retrieved from the Office of National Statistics. MACE was defined as cardiovascular death, myocardial infarction in the distribution of the anomalous coronary artery, revascularisation in the distribution of the anomalous coronary artery or aborted SCD. Definition and adjudication of MACE was performed blinded to the coronary anomaly classification.

\section{CMR pulse sequences}

CMR pulse sequences were performed using a protocol which included a contemporary (at the time of patient study) coronary magnetic resonance angiography pulse sequence. A low-resolution coronary survey scan was initially performed during free breathing, using a respiratory navigator. For a targeted approach CMR was performed as follows: for the right coronary artery (RCA) double-oblique three dimensional volume along the longaxis of the RCA; for the left coronary system a doubleoblique transverse three dimensional volume centred on 
the left main stem through the proximal left anterior descending and left circumflex arteries. For anomalous coronaries separate targeted views were typically acquired using a 3 point planning technique. 3-Dimensional targeted volumes were acquired using a three-dimensional gradient-echo sequence. Typical pulse sequence parameters: TE $2.2 \mathrm{~ms}$, TR $7.7 \mathrm{~ms}$, flip angle $25^{\circ}$, T2 and fat saturation pre-pulses, matrix $512 \times 360$, field of view $360 \mathrm{~mm}$, 20 slices with slice thickness of $1.5 \mathrm{~mm}$, acquired voxel size of $0.7 \times 1.0 \mathrm{~mm}$ (reconstructed to $0.7 \times 0.7 \mathrm{~mm}$ ). Full details previously reported [13].

More recent techniques included a three dimensional whole heart acquisition. For this, timing of the diastolic coronary rest period was estimated from a high temporal resolution four-chamber free breathing cine scan. Three dimensional whole heart coronary MR angiography was acquired using a balanced SSFP sequence and a respiratory navigator to compensate for respiratory motion during free breathing. Typical pulse sequence parameters: TE $2.3 \mathrm{~ms}$, TR $4.6 \mathrm{~ms}$, flip angle $100^{\circ}$, T2 and fat saturation pre-pulses, duration of acquisition up to $120 \mathrm{~ms}$ per R-R interval (determined by length of diastolic rest period), matrix $304 \times 304$, field of view $320-460 \mathrm{~mm}$, slice thickness $0.9 \mathrm{~mm}, 100-120$ slices as required, acquired in-plane voxel size of $1.0 \times 1.0 \mathrm{~mm}$ (reconstructed to $0.5 \times 0.5 \mathrm{~mm}$ ) [14].

\section{Statistics}

Data analysis was performed using SSPS 17.0 for Windows (SPSS, Chicago, Illinois, USA). Data are presented as mean \pm SD or median (IQR) as appropriate. Ordinal data were compared using the Mann-Whitney $U$ and $X^{2}$ tests. Two-tailed testing with a probability value of $\leq 0.05$ was considered statistically significant. Kaplan-Meier curves were used to estimate the distribution of time to first cardiac event and differences between time to first event curves compared with the log-rank test.

\section{Results}

In total, 59,844 CMR scans were performed between March 1995 and April 2010 at the two CMR institutions. 172 consecutive patients $(0.3 \%)$ with coronary artery anomalies were retrospectively identified (90 and 82 from each centre) with a median age of 54 years (range 1-85; IQR 40-64). The median follow-up time was 4.3 years (IQR 2.5-7.8) with a maximum of 15.6 years. At the time of follow-up, 160 patients were alive (93\%), 10 deceased (6\%) and 2 lost to follow-up. The distribution of classified coronary anomalies are detailed in Table 2 and a selection of coronary anomalies imaged by CMR are shown in Figure 1. There were no cases where the anatomy could not be determined.

Of the 172 patients, 116 had ACAOS (61 and 55 from each centre) with a median follow-up of 4.6 years. Of
Table 2 Distribution of the coronary anomalies in the joint CMR Databases $(\mathbf{n}=\mathbf{1 7 2})$

\begin{tabular}{ccc}
\hline Classification & Number & Age (median, range) \\
\hline $1 a$ & 13 & $58,8-73$ \\
$1 b$ & 8 & $36,1-73$ \\
$2 a$ & 34 & $55,13-78$ \\
$2 b$ & 0 & \\
$3 a$ & 0 & \\
$3 b$ & 33 & $58,25-78$ \\
$4 a$ & 4 & $56,30-70$ \\
$4 b$ & 6 & $19,15-41$ \\
$5 a$ & 13 & $60,29-85$ \\
$5 b$ & 5 & $70,34-80$ \\
$6 a$ & 11 & $36,15-64$ \\
$6 b$ & 2 & $53,47-59$ \\
$6 c$ & 18 & $56,18-76$ \\
7 & 25 & $46,8-78$ \\
\hline
\end{tabular}

these, 110 were alive (95\%), 5 deceased (4.3\%) and 1 lost to follow-up (1\%). 21 patients had a separate right coronary artery (RCA) and left main stem (LMS) from the right coronary sinus of which 13 had an IAC of the LMS between the aorta and PA. Separate origins of both coronary arteries from the left aortic sinus all of which took an IAC were present in 34 patients. An anomalous circumflex from the opposite sinus occurred in 33 patients none of which took an IAC. An anomalous left anterior descending artery from the opposite sinus was present in 10 patients, with 4 following an IAC route. Finally, 18 had a single coronary artery of which 13 passed interarterially. Therefore of the 116 patients with ACAOS, 64 patients (55\%) had an inter-arterial course and 52 (45\%) without an inter-arterial course (Table 3). There was no statistical difference in the age of the two ACAOS populations (with or without IAC) $(\mathrm{P}=0.63)$.

Of those patients with ACAOS there were in total 58 MACE (5 cardiovascular deaths, 5 percutaneous coronary interventions (PCI) to the anomalous artery, 24 underwent surgical revascularisation to the anomalous territory and 24 had a documented myocardial infarction in the anomalous coronary artery territory). All PCI was performed for coronary artery disease with coronary stenosis visually measuring $>70 \%$ luminal stenosis. All myocardial infarctions were spontaneous related to atherosclerotic plaque (type 1) [15]. The mortality rate from cardiovascular causes was 4.3\% (5 cardiovascular deaths in 116 ACAOS patients) during the median follow up period of 4.6 years. Of the 5 deaths 4 were from a documented myocardial infarction (all with a rise of cardiac biomarkers and ECG changes) and one 


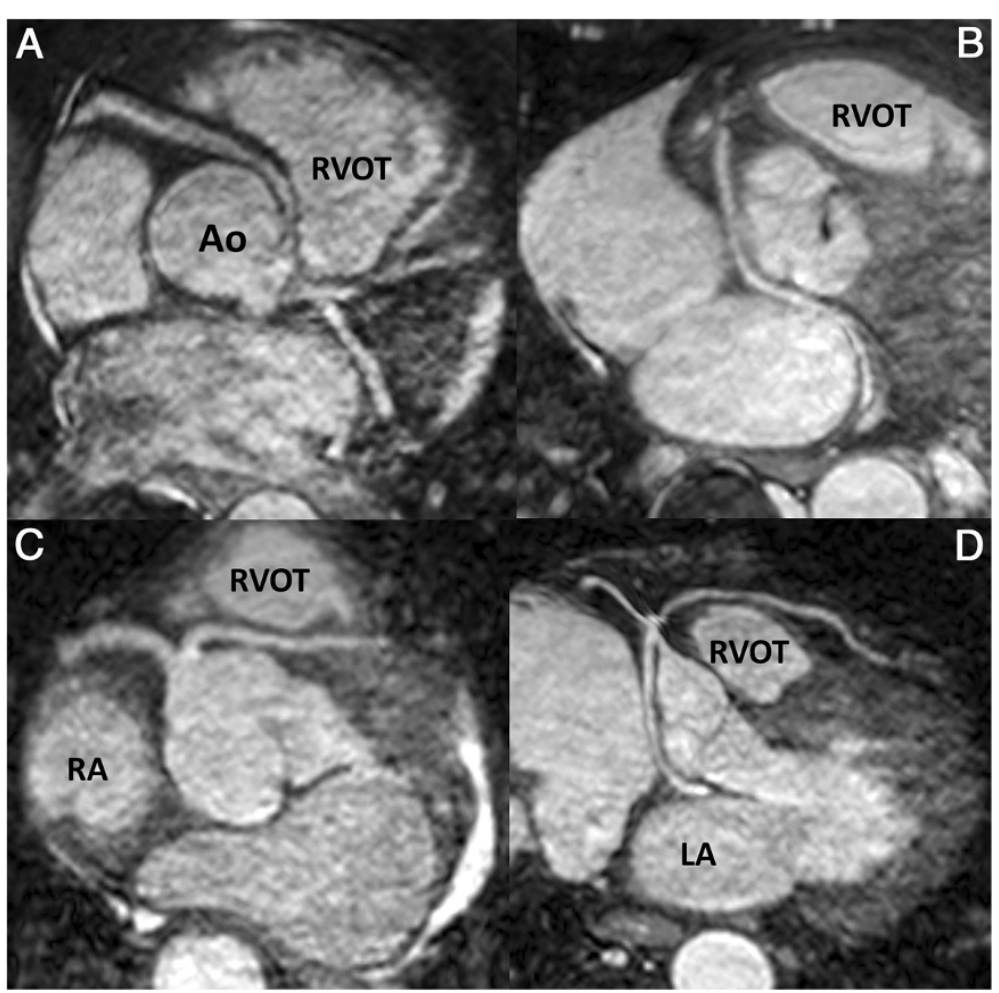

Figure 1 Examples of several different anomalous coronary arteries imaged by CMR: (A) Right coronary artery originating from the left coronary cusp passing anteriorly (class 2a), (B) Circumflex artery arising from the right coronary cusp (RCC) passing posteriorly (class 3b), (C) Left anterior descending (LAD) artery from the RCC anteriorly passing between the RVOT and aorta (class 4a) and (D) single ostium coronary system arising from the RCC with a retro-aortic circumflex artery and a pre-pulmonic LAD (class 5b). Images reconstructed using SoapBubble ${ }^{\mathrm{TM}}$ software (Philips Medical Systems). Ao - Aorta; RVOT - Right Ventricular Outflow Tract; RA - Right Atrium; LA - Left Atrium.

death from chronic heart failure secondary to ischaemic heart disease.

47 MACE occurred in patients with ACAOS and an IAC and 11 in those without an IAC $(\mathrm{p}<0.0001)$. There was significantly higher risk of both surgical revascularisation and myocardial infarction in the IAC group, with similar numbers of percutaneous revascularisation and cardiovascular deaths (Table 4). Age of first MACE was lower in those coronary abnormalities with an IAC $(\mathrm{p}<0.0001)$ (Figure 2). The distribution of major cardiovascular events by coronary anomaly is presented in Table 5.

Table 3 Distribution of anomalous coronary arteries originating from the opposite sinus with and without inter arterial course

\begin{tabular}{lcc}
\hline & Number & Age (median, range) \\
\hline Total ACAOS & 116 & $54,1-85$ \\
- ACAOS with inter-arterial course & 64 & $56,8-85$ \\
- ACAOS without inter-arterial course & 52 & $53,1-80$ \\
\hline
\end{tabular}

ACAOS = anomalous coronary artery originating from the opposite sinus of Valsalva.

\section{Discussion}

This study has shown the distribution of coronary artery anomalies imaged by CMR in two large tertiary cardiac centres over the previous 15 years. Our study demonstrates the prognostic significance of an inter-arterial course for an anomalous coronary artery originating from the opposite sinus of Valsalva (ACAOS) passing between the aorta and pulmonary artery. We have also shown significantly higher myocardial infarction and surgical revascularisation rates for this group of anomalous arteries in those patients referred for CMR, over a median 4.6 year follow-up period.

Table 4 Major Adverse Cardiovascular Events in patients with an anomalous coronary artery originating from the opposite sinus of Valsalva (ACAOS) $(n=116)$

\begin{tabular}{lccc}
\hline & $\begin{array}{c}\text { ACAOS with } \\
\text { IAC }(\mathbf{n}=\mathbf{6 4})\end{array}$ & $\begin{array}{c}\text { ACAOS without } \\
\text { IAC }(\mathbf{n}=\mathbf{5 2})\end{array}$ & P value \\
\hline Cardiovascular Deaths, $\mathbf{n}$ & 3 & 2 & NS \\
PCI, $\mathbf{n}$ & 3 & 2 & NS \\
Surgical revascularisation, $\mathbf{n}$ & 23 & 1 & $\mathrm{P}<0.0001$ \\
Myocardial Infarction, $\mathbf{n}$ & 18 & 6 & $\mathrm{P}<0.05$ \\
\hline
\end{tabular}




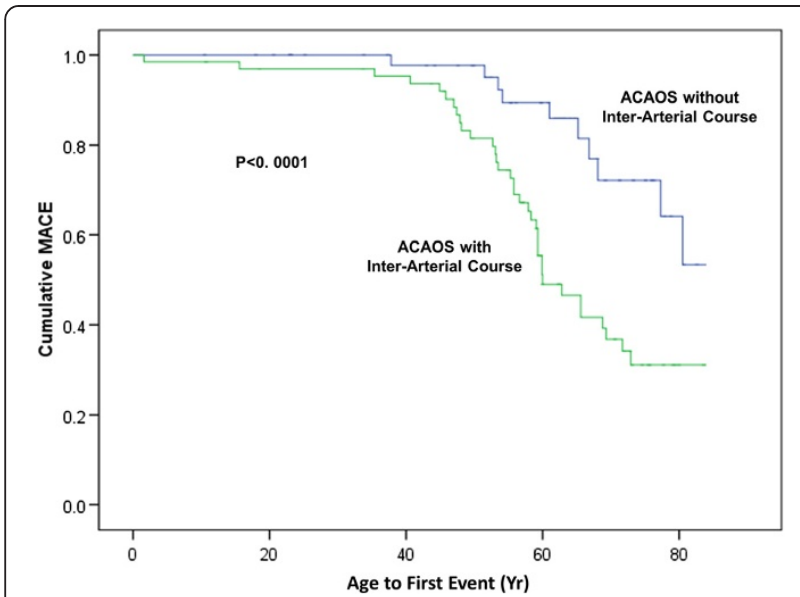

Figure 2 Kaplan-Meier curves showing the age at which the first major adverse cardiovascular event occurred, demonstrating a significant difference (log rank test, $p<0.0001$ ) between those anomalous coronary arteries from the opposite sinus (ACAOS) with an inter-arterial course (IAC) and those without IAC.

Invasive X-ray angiography has traditionally been the diagnostic imaging test to identify coronary anomalies however the presence of an anomalous vessel may only be suspected after the procedure (e.g. after unsuccessful catheterisation). CMR has a number of advantages for diagnosing coronary artery anomalies. The non-invasive technique does not require contrast agents or ionising radiation, which is an important consideration particularly in children and young adults. The dose and stochastic effects of X-ray radiation are frequently misjudged [16] and the risk of developing a solid tumour is estimated at 1:2500

Table 5 Major Adverse Cardiovascular Events in patients by coronary anomaly in those patients with anomalous coronary artery originating from the opposite sinus of Valsalva (ACAOS)

\begin{tabular}{|c|c|c|c|c|c|c|}
\hline \multirow[t]{2}{*}{ Classification } & \multirow[t]{2}{*}{ Number } & \multicolumn{4}{|c|}{ Major Adverse Cardiovascular Event } & \multirow{2}{*}{$\begin{array}{l}\text { Total } \\
\text { MACE }\end{array}$} \\
\hline & & $\begin{array}{l}\text { CV } \\
\text { Death }\end{array}$ & $\mathrm{PCl}$ & $\begin{array}{l}\text { Surgical } \\
\text { revascularisation }\end{array}$ & MI & \\
\hline $1 \mathrm{a}$ & 13 & 0 & 1 & 7 & 5 & 13 \\
\hline $1 b$ & 8 & 0 & 1 & 0 & 2 & 3 \\
\hline $2 \mathrm{a}$ & 34 & 1 & 1 & 12 & 6 & 20 \\
\hline $2 b$ & 0 & 0 & 0 & 0 & 0 & 0 \\
\hline $3 a$ & 0 & 0 & 0 & 0 & 0 & 0 \\
\hline $3 b$ & 33 & 1 & 1 & 1 & 4 & 7 \\
\hline $4 a$ & 4 & 0 & 0 & 0 & 2 & 2 \\
\hline $4 b$ & 6 & 0 & 0 & 0 & 0 & 0 \\
\hline $5 a$ & 13 & 2 & 1 & 4 & 5 & 12 \\
\hline $5 b$ & 5 & 1 & 0 & 0 & 0 & 1 \\
\hline
\end{tabular}

CV death - Cardiovascular death; PCI - Percutaneous coronary intervention; $\mathrm{MI}$ - myocardial infarction. diagnostic coronary angiographic procedures $[17,18]$. Furthermore CMR clarifies the spatial relationship of these arteries with respect to the aorta and the pulmonary artery, which we and others have demonstrated confers differential risk; this is also important in surgical planning. The application of CMR for the detection and documentation of the origin and course of coronary anomalies is well established [19-22] and as such CMR is a recognised class I indication in international guidelines [23,24].

Anomalous coronary arteries cover a wide range of conditions the majority of which have no clinical significance [25]. Post mortem studies from both the military and in young athletes have shown that ACAOS is associated with a higher risk of SCD. The risk is higher in athletes with ACAOS, representing a 79 times higher relative risk than in non-athletic individuals [4] which is limited to those ACAOS taking an inter-arterial course between the aorta and main pulmonary artery. In one 25 year review of 126 non-traumatic military deaths, a high proportion of deaths (33\%) were attributable to ACAOS and it was a more common cause of death than both myocarditis and hypertrophic cardiomyopathy [26]. In this review, the risk was exclusively limited to only those with a left-ACAOS (anomalous origination of the left coronary artery from the right sinus of Valsalva [27]) passing inter-arterially. However, there is also evidence that right-ACAOS (anomalous origination of the right coronary artery from the left sinus of Valsalva) may cause SCD, with one registry in athletes attributing 27 deaths to ACAOS (4 of which were a right coronary artery from the left coronary sinus) [28]. This registry also confirmed the relationship with exertion, detailing that all deaths occurred either during or shortly after exercise [28]. The prognostic risk of right-ACAOS was further corroborated by a contemporary review of consecutive patients referred for CT coronary angiography over a 4 year period, demonstrating malignant features which interestingly in this series were exclusive to rightACAOS [29]. Those high risk features of an intramural inter-arterial course and severe lateral compression of the proximal vessel have been shown to have a clear relationship with ventricular fibrillation [30].

Whilst there is evidence that ACAOS is associated with SCD, there are little data regarding myocardial infarction and rates of revascularisation in the anomalous artery territory. Chaitman et al. [31] demonstrated the existence of coronary atheroma in 6 out of 17 patients (35\%) with ACAOS, significantly higher than the $8 \%$ documented in a normal population [32]. Furthermore a history of MI and in patients with ACAOS with IAC and non-atherosclerotic arteries has been documented [31]. Although one long term follow-up of 87 patients with right-ACAOS and an inter-arterial course showed only 3 myocardial infarctions (3.4\%) over a 2.5 year follow-up 
[33] significantly lower than $15 \%$ we observe over 4.3 years in this sub-group (and 28\% overall in our cohort). There are only a few published cases showing myocardial infarction in the anomalous territory.

The mechanism of myocardial infarction and SCD in ACAOS is not clear. The risk from ACAOS has been traditionally thought to be related directly to the haemodynamic significance of the inter-arterial course of the anomalous vessel, with SCD and myocardial infarction related to rising pressure in both aorta and pulmonary artery during exercise causing a scissoring or kinking of the vessel [34]. Angelini, however, has since developed a theory of intussusception, eloquently demonstrating with intravascular ultrasound (IVUS) that the main mechanism of ischaemia originates with hypoplasia and lateral luminal compression in the proximal vessel, which runs intramurally at the aortic root whilst crossing the aorto-pulmonary septum and demonstrated worsening of the proximal narrowing during physiological stress testing [35,36]. An extramural course has never been observed in those ACAOS with an interarterial course [25] however an intramural course has been demonstrated in some ACAOS without an inter-arterial course [25,27].

The location of the anomalous vessel in relation to the pulmonary trunk is therefore important and one long term follow up of right-ACAOS with inter-arterial course diagnosed by CT demonstrated higher MACE in those with a high inter-arterial course (RCA ostium located above the pulmonary valve) as opposed to low interarterial course (RCA ostium below pulmonary valve) and therefore hypothesised that the high inter-arterial course is more susceptible to compression between the aortic root and main pulmonary artery during systole [33]. The difference in MACE in this study was driven by unstable angina admissions and there was no statistical difference between myocardial infarction and cardiovascular death in both groups [33].

Krasuski et al. [10]. followed-up 301 patients with ACAOS (54 with an IAC) and demonstrated that ACAOS with an inter-arterial course were almost twice as likely to undergo surgical intervention and showed a higher rate of significant coronary artery disease in the distribution of the anomalous vessel (50\% vs. $25 \%$, $\mathrm{p}=0.02$ ) in those undergoing surgical intervention. Those undergoing surgery were also more likely to have had a myocardial infarction and an abnormal cardiac stress test [10]. They did not however, show any difference in the incidence of myocardial infarction between those with or without IAC, which is contrary to our data. Our study demonstrates a significantly higher rate of myocardial infarction in the territory of the anomalous coronary artery with 18 events in 64 ACAOS with IAC and only 6 in 52 ACAOS without IAC $(\mathrm{p}<0.05)$. The lack of significance in myocardial infarction rates in the study by Krasuski may be due to the preference for early surgical intervention with $52 \%$ of patients with an inter-arterial course undergoing cardiac surgery, and after the year 2000, a 4:1 ratio of surgical versus medical management.

Krasuski also demonstrated a substantially higher mortality rate of $44 \%$ over a mean 9.2 year follow-up which is in contrast to the $4.3 \%$ mortality rate over 4.6 years in our study. Despite the high mortality rate they showed no difference in long term survival between those with or without IAC, which accords with our results, although contradicts the data from post-mortem studies. This lack of significance is unlikely to be due to the size of our cohort $(n=116)$ as this is higher than the population in many autopsy studies which reveal a statistical difference between the ACAOS with or without IAC. This may, however, reflect the limited number of young patients in our cohort with only $11 \%$ under the age of 30 years and a median age of 54 years. The under 30 age group in particular have been shown to have a significantly higher risk of SCD and exercise related death $[8,37]$.

\section{Limitations}

This is a retrospective review of a selected population of patients referred to tertiary CMR centres for documentation of their coronary anatomy and therefore subject to referral bias. It is recognised that all cardiovascular MR scans performed showing coronary artery abnormalities may not have been identified, for example some those with complex adult congenital heart disease and incidental coronary anomalies could have been missed; we were careful to include all those with anomalous coronaries as the primary referral indication for CMR. The mean age of the patients was 54 years and therefore does not include many of the younger high risk patients who may have already died from SCD. We were unable to fully document referral indication, cardiovascular risk profile, co-morbidities and medication which may have influenced patient outcomes. Also, invasive angiography was not mandated in all to confirm the presence or absence of epicardial coronary artery disease. However we were careful to focus on hard cardiovascular events that could easily be validated. We were also meticulous in determining that myocardial infarction and revascularisation had to be related to the aberrant vessel in order to count as MACE for the purpose of our study. Whilst it is recognised that surgical revascularisation may have been performed for primary prevention on knowledge of the coronary anatomy in selected cases, we note the very large difference in surgical revascularisation between ACAOS with IAC $(23,36 \%)$ and those without (1, 2\%). Furthermore there remained a significant difference in the number of myocardial infarctions (18 vs. 6) between the ACAOS with and without IAC. 


\section{Conclusion}

In conclusion, we have shown distribution of anomalous coronary arteries imaged by CMR over a 15 year period from two large tertiary cardiac centres. This represents one of the largest series of anomalous coronary arteries, demonstrating that in life, patients with an anomalous coronary artery originating from the opposite sinus of Valsalva taking an inter-arterial course have higher rates of both myocardial infarction and surgical revascularisation during long-term follow up, compared to those without IAC.

\section{Consent}

Written informed consent was obtained from the patient for the publication of this report and any accompanying images.

\section{Abbreviations}

ACAOS: Anomalous coronary artery originating from the opposite sinus of Valsalva; CMR: Cardiovascular magnetic resonance; CT: Computed tomography; HCM: Hypertrophic cardiomyopathy; IAC: Inter-arterial course; IVUS: Intravascular ultrasound; LMS: Left main stem; MACE: Major adverse cardiovascular events; PA: Pulmonary artery; RCA: Right coronary artery; RVOT: Right ventricular outflow tract; SCD: Sudden cardiac death.
\end{abstract}

\section{Competing interest}

The authors declare that they have no competing interest.

\section{Authors' contributions}

DPR: Design, analysis and interpretation of data, drafting of the manuscript; AS: Analysis and interpretation of data; AT: Analysis and interpretation of data; AU: Interpretation of data, critical and intellectual revision of manuscript; PB: Analysis and interpretation of data; AK: Critical and intellectual revision of manuscript; AKM: Critical and intellectual revision of manuscript; MS: Critical and intellectual revision of manuscript; SP: Critical and intellectual revision of manuscript; DJP: Conception and design, critical and intellectual revision of manuscript. JPG: Conception and design, interpretation of data, drafting of manuscript. All authors have given approval of this manuscript for publication.

\section{Funding}

JPG and SP receive a research grant from Philips Healthcare. SP is funded by British Heart Foundation fellowship (FS/10/62/28409). DJP was supported from the NIHR Cardiovascular Biomedical Research Unit of Royal Brompton and Harefield NHS Foundation Trust and Imperial College London.

\section{Author details}

${ }^{1}$ Multidisciplinary Cardiovascular Research Centre (MCRC) \& Leeds Institute of Genetics, Health and Therapeutics, University of Leeds, Leeds, UK. ${ }^{2}$ Leeds Teaching Hospitals NHS Trust, Leeds General Infirmary, Leeds, UK. ${ }^{3} \mathrm{NIHR}$ Cardiovascular Biomedical Research Unit Royal Brompton Hospital, London, UK.

Received: 30 September 2013 Accepted: 17 March 2014 Published: 20 May 2014

\section{References}

1. Click RL, Holmes DR Jr, Vlietstra RE, Kosinski AS, Kronmal RA. Anomalous coronary arteries: location, degree of atherosclerosis and effect on survival-a report from the coronary artery surgery study. J Am Coll Cardiol. 1989; 13:531-7.

2. Yamanaka O, Hobbs RE. Coronary artery anomalies in 126,595 patients undergoing coronary arteriography. Cathet Cardiovasc Diagn. 1990; 21:28-40.

3. Maron BJ, Shirani J, Poliac LC, Mathenge R, Roberts WC, Mueller FO. Sudden death in young competitive athletes. Clinical, demographic, and pathological profiles. JAMA. 1996; 276:199-204.
4. Corrado D, Basso C, Rizzoli G, Schiavon M, Thiene G. Does sports activity enhance the risk of sudden death in adolescents and young adults? J Am Coll Cardiol. 2003; 42:1959-63.

5. Roberts WC, Siegel RJ, Zipes DP. Origin of the right coronary artery from the left sinus of valsalva and its functional consequences: analysis of 10 necropsy patients. Am J Cardiol. 1982; 49:863-8.

6. Cheitlin MD, De Castro CM, McAllister HA. Sudden death as a complication of anomalous left coronary origin from the anterior sinus of valsalva, a not-so-minor congenital anomaly. Circulation. 1974; 50:780-7.

7. Kragel $\mathrm{AH}$, Roberts WC. Anomalous origin of either the right or left main coronary artery from the aorta with subsequent coursing between aorta and pulmonary trunk: analysis of 32 necropsy cases. Am J Cardiol. 1988; 62:771-7.

8. Taylor AJ, Byers JP, Cheitlin MD, Virmani R. Anomalous right or left coronary artery from the contralateral coronary sinus: "High-risk" abnormalities in the initial coronary artery course and heterogeneous clinical outcomes. Am Heart J. 1997; 133:428-35.

9. Frommelt PC, Sheridan DC, Berger S, Frommelt MA, Tweddell JS. Ten-year experience with surgical unroofing of anomalous aortic origin of a coronary artery from the opposite sinus with an interarterial course. J Thorac Cardiovasc Surg. 2011; 142:1046-51.

10. Krasuski RA, Magyar D, Hart S, Kalahasti V, Lorber R, Hobbs R, Pettersson G, Blackstone E. Long-term outcome and impact of surgery on adults with coronary arteries originating from the opposite coronary cusp. Circulation. 2011; 123:154-62.

11. Angelini P, Velasco JA, Flamm S. Coronary anomalies: incidence, pathophysiology, and clinical relevance. Circulation. 2002; 105:2449-54.

12. Wilkins CE, Betancourt B, Mathur VS, Massumi A, De Castro CM, Garcia E, Hall RJ. Coronary artery anomalies: a review of more than 10,000 patients from the clayton cardiovascular laboratories. Tex Heart Inst J. 1988; 15:166-73.

13. Kim WY, Danias PG, Stuber M, Flamm SD, Plein S, Nagel E, Langerak SE, Weber OM, Pedersen EM, Schmidt M, Botnar RM, Manning WJ. Coronary magnetic resonance angiography for the detection of coronary stenoses. N Engl J Med. 2001; 345:1863-9.

14. Greenwood JP, Maredia N, Radjenovic A, Brown JM, Nixon J, Farrin AJ, Dickinson C, Younger JF, Ridgway JP, Sculpher M, Ball SG, Plein S. Clinical evaluation of magnetic resonance imaging in coronary heart disease: the ce-marc study. Trials. 2009; 10:62.

15. Thygesen K, Alpert JS, Jaffe AS, Simoons ML, Chaitman BR, White HD. Third universal definition of myocardial infarction. Nat Rev Cardiol. 2012; 9:620-33.

16. Shiralkar S, Rennie A, Snow M, Galland RB, Lewis MH, Gower-Thomas K. Doctors' knowledge of radiation exposure: questionnaire study. BMJ. 2003; 327:371-2.

17. Razavi R, Hill DL, Keevil SF, Miquel ME, Muthurangu V, Hegde S, Rhode K, Barnett M, Van Vaals J, Hawkes DJ, Baker E. Cardiac catheterisation guided by mri in children and adults with congenital heart disease. Lancet. 2003; 362:1877-82.

18. NRPB. Guidelines on Patient Dose to Promote the Optimisation of Protection for Diagnostic Medical Exposures. Vol 10: No. 1 Radiological Protection Board, Chilton. : ; 1999.

19. McConnell MV, Ganz P, Selwyn AP, Li W, Edelman RR, Manning WJ. Identification of anomalous coronary arteries and their anatomic course by magnetic resonance coronary angiography. Circulation. 1995; 92:3158-62.

20. Post JC, Van Rossum AC, Bronzwaer JG, De Cock CC, Hofman MB, Valk J, Visser CA. Magnetic resonance angiography of anomalous coronary arteries. A new gold standard for delineating the proximal course? Circulation. 1995; 92:3163-71.

21. Taylor AM, Thorne SA, Rubens MB, Jhooti P, Keegan J, Gatehouse PD, Wiesmann F, Grothues F, Somerville J, Pennell DJ. Coronary artery imaging in grown up congenital heart disease: complementary role of magnetic resonance and x-ray coronary angiography. Circulation. 2000; 101:1670-8.

22. Bunce NH, Lorenz CH, Keegan J, Lesser J, Reyes EM, Firmin DN, Pennell DJ. Coronary artery anomalies: assessment with free-breathing threedimensional coronary mr angiography. Radiology. 2003; 227:201-8.

23. Pennell DJ, Sechtem UP, Higgins CB, Manning WJ, Pohost GM, Rademakers FE, Rossum AC, Shaw LJ, Yucel EK. Clinical indications for cardiovascular magnetic resonance (cmr): consensus panel report. Eur Heart J. 2004; 25:1940-65 
24. Hundley WG, Bluemke DA, Finn JP, Flamm SD, Fogel MA, Friedrich MG, Ho VB, Jerosch-Herold M, Kramer CM, Manning WJ, Patel M, Pohost GM, Stillman AE, White RD, Woodard PK. Accf/acr/aha/nasci/scmr 2010 expert consensus document on cardiovascular magnetic resonance: a report of the american college of cardiology foundation task force on expert consensus documents. Circulation. 2010; 121:2462-508.

25. Angelini P. Coronary artery anomalies: an entity in search of an identity. Circulation. 2007; 115:1296-305.

26. Eckart RE, Scoville SL, Campbell CL, Shry EA, Stajduhar KC, Potter RN, Pearse LA, Virmani R. Sudden death in young adults: a 25-year review of autopsies in military recruits. Ann Intern Med. 2004; 141:829-34.

27. Angelini P, Walmsley RP, Libreros A, Ott DA. Symptomatic anomalous origination of the left coronary artery from the opposite sinus of valsalva. Clinical presentations, diagnosis, and surgical repair. Tex Heart Inst J. 2006; 33:171-9.

28. Basso C, Maron BJ, Corrado D, Thiene G. Clinical profile of congenital coronary artery anomalies with origin from the wrong aortic sinus leading to sudden death in young competitive athletes. J Am Coll Cardiol. 2000; 35:1493-501.

29. Opolski MP, Pregowski J, Kruk M, Witkowski A, Kwiecinska S, Lubienska E, Demkow M, Hryniewiecki T, Michalek P, Ruzyllo W, Kepka C. Prevalence and characteristics of coronary anomalies originating from the opposite sinus of valsalva in 8,522 patients referred for coronary computed tomography angiography. Am J Cardiol. 2013; 111:1361-7.

30. Jo Y, Uranaka Y, Iwaki H, Matsumoto J, Koura T, Negishi K. Sudden cardiac arrest: associated with anomalous origin of the right coronary artery from the left main coronary artery. Tex Heart Inst J. 2011; 38:539-43.

31. Chaitman BR, Lesperance J, Saltiel J, Bourassa MG. Clinical, angiographic, and hemodynamic findings in patients with anomalous origin of the coronary arteries. Circulation. 1976; 53:122-31.

32. Tuzcu EM, Kapadia SR, Tutar E, Ziada KM, Hobbs RE, McCarthy PM, Young JB, Nissen SE. High prevalence of coronary atherosclerosis in asymptomatic teenagers and young adults: evidence from intravascular ultrasound. Circulation. 2001; 103:2705-10.

33. Lee HJ, Hong YJ, Kim HY, Lee J, Hur J, Choi BW, Chang HJ, Nam JE, Choe KO, $\mathrm{Kim}$ YJ. Anomalous origin of the right coronary artery from the left coronary sinus with an interarterial course: subtypes and clinical importance. Radiology. 2012; 262:101-8.

34. Grollman JH Jr, Mao SS, Weinstein SR. Arteriographic demonstration of both kinking at the origin and compression between the great vessels of an anomalous right coronary artery arising in common with a left coronary artery from above the left sinus of valsalva. Cathet Cardiovasc Diagn. 1992; 25:46-51.

35. Hariharan R, Kacere RD, Angelini P. Can stent-angioplasty be a valid alternative to surgery when revascularization is indicated for anomalous origination of a coronary artery from the opposite sinus? Tex Heart Inst J. 2002; 29:308-13.

36. Angelini P, Velasco JA, Ott D, Khoshnevis GR. Anomalous coronary artery arising from the opposite sinus: descriptive features and pathophysiologic mechanisms, as documented by intravascular ultrasonography. I Invasive Cardiol. 2003; 15:507-14.

37. Taylor AJ, Rogan KM, Virmani R. Sudden cardiac death associated with isolated congenital coronary artery anomalies. J Am Coll Cardiol. 1992; 20:640-7.

doi:10.1186/1532-429X-16-34

Cite this article as: Ripley et al:: The distribution and prognosis of anomalous coronary arteries identified by cardiovascular magnetic resonance: 15 year experience from two tertiary centres. Journal of Cardiovascular Magnetic Resonance 2014 16:34.

\section{Submit your next manuscript to BioMed Central and take full advantage of:}

- Convenient online submission

- Thorough peer review

- No space constraints or color figure charges

- Immediate publication on acceptance

- Inclusion in PubMed, CAS, Scopus and Google Scholar

- Research which is freely available for redistribution

Submit your manuscript at www.biomedcentral.com/submit 